\title{
Uniaxial Compressive Response and Constitutive Modeling of Selected Polymers Over a Wide Range of Strain Rates
}

\author{
Kenji Nakai • Takashi Yokoyama
}

Received: 16 October 2014/ Accepted: 2 January 2015/Published online: 21 January 2015

(C) Society for Experimental Mechanics, Inc 2015

\begin{abstract}
The present work deals with constitutive modeling of the compressive stress-strain response of selected polymers at strain rates from $10^{-3}$ to nearly $10^{3} \mathrm{~s}^{-1}$. Six different commercially available extruded polymers-ABS, HDPE, PC, POM, PP and PVC-are tested at room temperature. Cylindrical specimens with a slenderness ratio (=length/diameter) of 0.5 are used in high strain-rate tests, and those with the slenderness ratios of 1.0 and 2.0 are used in low and intermediate strain-rate tests. High strain-rate compressive stress-strain loops up to a strain of nearly 0.08 are obtained on a standard split Hopkinson pressure bar. Low and intermediate strain-rate compressive ones are measured on an Instron testing machine. By fitting experimental loading stress-strain data to a modified Ramberg-Osgood equation, material parameters are uniquely determined using a linear leastsquares procedure. Experimental results indicate that all polymers tested exhibit intrinsic dynamic viscoelasticplastic characteristics and a higher elastic after-effect following complete unloading. It is shown that the modified Ramberg-Osgood constitutive model is appropriate for describing the monotonic loading compressive stress-strain relations of the three semi-crystalline polymers over a wide range of strain rates. The advantages and limitations of the constitutive model are also discussed.
\end{abstract}

Keywords Compressive stress-strain - Hopkinson bar . Low mechanical impedance · Modified Ramberg-Osgood model $\cdot$ Polymers $\cdot$ Strain rate $\cdot$ Viscoelastic-plastic behavior

K. Nakai $(\bowtie) \cdot T$. Yokoyama

Department of Mechanical Engineering, Okayama University of

Science, 1-1 Ridai-cho, Kitaku, Okayama 700-0005, Japan

e-mail: nakai@mech.ous.ac.jp

\section{Introduction}

Polymeric materials with low mechanical impedance have been extensively used as structural materials for aircraft, automotive, mechanical and electronic components, mainly because of higher specific strength as well as higher corrosion resistance. These components are often subjected to dynamic loading in service environments. It is, therefore, essential to obtain the high strain-rate response of polymers. To date, many attempts have been made to characterize the impact behavior of thermoplastic (amorphous and semicrystalline) and thermoset polymers using various techniques. Many workers [1-4] evaluated the impact strength and fracture toughness of several polymers by a Charpy or Izod test. Nevertheless, impact stress-strain curves cannot be achieved with these test methods. The impact compressive [5-29], tensile [8, 14, 16, 30-35] and torsional [32, 36] stress-strain properties of various polymers were accurately determined using a classic [37] or modified split Hopkinson pressure bar (SHPB). The effects of strain rate and temperature on stress-strain characteristics of various polymers were examined using a drop-weight apparatus $[10,18,38$ 41] and a SHPB [18-20, 31]. Briscoe and Hutchings [39], and Rae et al. [42] evaluated flow stresses of HDPE and PEEK at very high strain rates of nearly $10^{4} \mathrm{~s}^{-1}$ under temperatures of 20 and $100{ }^{\circ} \mathrm{C}$ in Taylor tests. Temperature rise in thermoplastic polymers (PA-66, PC, PMMA, PP and PVC) and thermoset polymer (Epon 862/W epoxy) during high-rate deformation was measured using either an infrared detector system [14, 15, 22] or a thermocouple [7, 29]. More recently, Furmanski et al. [43] have developed a modified Taylor test method for studying higher strain-rate and larger strain response of four different polymers (HDPE, PCTFE, Polyurea and PTFE) in tension. Millett and Bourne [44, 45] applied a plate-impact technique for measuring the Hugoniot 
of PMMA and three other polymers (PE, PP and PS) under shock loading. To accurately represent the high strain-rate stress-strain curves for polymers, we need to develop their rate-dependent constitutive equations. So far, many constitutive equations have been proposed to express stress-strain curves for thermoplastic and thermoset polymers over a wide range of strain rates and temperatures. Several mathematical models, such as a nonlinear exponential model [13], nonlinear power laws [24, 34] and nonlinear exponential and hyperbolic models [46] based on a Johnson-Cook formulation were used to simulate compressive and tensile stressstrain response of epoxy and acrylic resins up to a strain of nearly 0.10 at different strain rates. Rate-dependent compressive and tensile stress-strain curves at larger strains for semi-crystalline polymers (polyester resins and PTFE) were represented by nonlinear viscoelastic-plastic models [8, 47, 48] and a Zerilli-Armstrong model [21]. An initial linear elastic, strain softening followed by hardening behavior after yielding at strain rates from $10^{-4}$ to $10^{4} \mathrm{~s}^{-1}$ for amorphous and thermoset polymers in compression was described using molecularly-based viscoelastic-plastic models [20, 49-51]. Richeton et al. [52-54] and Khan et al. [55] discussed strainrate and temperature dependence of compressive stressstrain response for amorphous polymers (PAI, PC and PMMA) and a thermoset polymer (PU) using one-dimensional and three-dimensional thermo-mechanical models. Nevertheless, it is very difficult to perform numerical simulations of dynamic response of polymers using these constitutive models with a large number of parameters.

The objective of the present work is to model the compressive stress-strain response of selected polymers at strain rates from $10^{-3}$ to nearly $10^{3} \mathrm{~s}^{-1}$ using a simple strain-rate dependent constitutive equation. Six different commercial extruded polymers were tested at room temperature. Cylindrical specimens with a slenderness ratio (=length $l /$ diameter $d$ ) of 0.5 were used in the high strain- rate tests, and those with $l / d$ of 1.0 and 2.0 were used in the low and intermediate strain-rate tests. Compressive stressstrain loops at strain rates up to nearly $10^{3} \mathrm{~s}^{-1}$ were accurately determined on the conventional SHPB. The corresponding low and intermediate strain-rate stressstrain loops were measured on an Instron testing machine (Model 5500R). A rate-dependent Ramberg-Osgood constitutive equation was applied to model experimental stress-strain data over a wide range of strain rates.

\section{Experimental Details}

Test Polymers and Specimen Preparation

Three amorphous polymers (ABS, PC and PVC) and three semi-crystalline polymers (HDPE, POM and PP) were chosen for this work. Their full chemical names and suppliers of polymer rods are listed in Table 1. The six different extruded polymers tested are shown in Fig. 1. Cylindrical specimens were machined from the extruded rods into short cylinders with a diameter of $9 \mathrm{~mm}$. The specimen end surfaces were carefully polished to a surface roughness of approximately $0.4-0.6 \mu \mathrm{m} R_{\mathrm{a}}$ with emery papers. The shape and dimensions of the static and impact compression specimens are given in Tables 2 and 3. The slenderness ratios of the static specimens were taken as $l / d=1.0$ and 2.0. The slenderness ratio of 1.5 or 2.0 is recommended in the ASTM Designation E9-89a [56], while that of the impact specimen was taken as $l / d=0.5$. This is because the slenderness ratios of 0.5 or less can be effective in the SHPB testing of low-impedance materials to minimize wave attenuation in the specimen [57]. All specimens were tested in the as-received state (i.e., not subjected to heat treatment).

Table 1 Full chemical names and suppliers of six different extruded polymer rods

\begin{tabular}{lll}
\hline Abbreviation & Chemical name & Supplier \\
\hline $\mathrm{ABS}^{\mathrm{a}}$ & Acrylonitrile butadiene styrene & NAC Group Co., Ltd., Fukui, Japan \\
$\mathrm{HDPE}^{\mathrm{b}}$ & High density polyethylene & Toyama Keisozai Co., Ltd., Toyama, Japan \\
$\mathrm{PC}^{\mathrm{c}}$ & Polycarbonate & Toyo Plastic Seiko Co., Ltd., Tokyo, Japan \\
$\mathrm{POM}^{\mathrm{b}}$ & Polyoxymethylene & Polyplastics Co., Ltd., Tokyo, Japan \\
$\mathrm{PP}^{\mathrm{b}}$ & Polypropylene & NAC Group Co., Ltd., Fukui, Japan \\
$\mathrm{PVC}^{\mathrm{a}}$ & Polyvinylchloride & Takiron Co., Ltd., Osaka, Japan \\
\hline
\end{tabular}

\footnotetext{
${ }^{a}$ Amorphous polymer

b Semi-crystalline polymer

c $70 \%$ crystallinity

${ }^{\text {d }}$ Commercial name Duracon ${ }^{\circledR}$ M90-44 of $65 \%$ crystallinity

e $60 \%$ crystallinity
} 


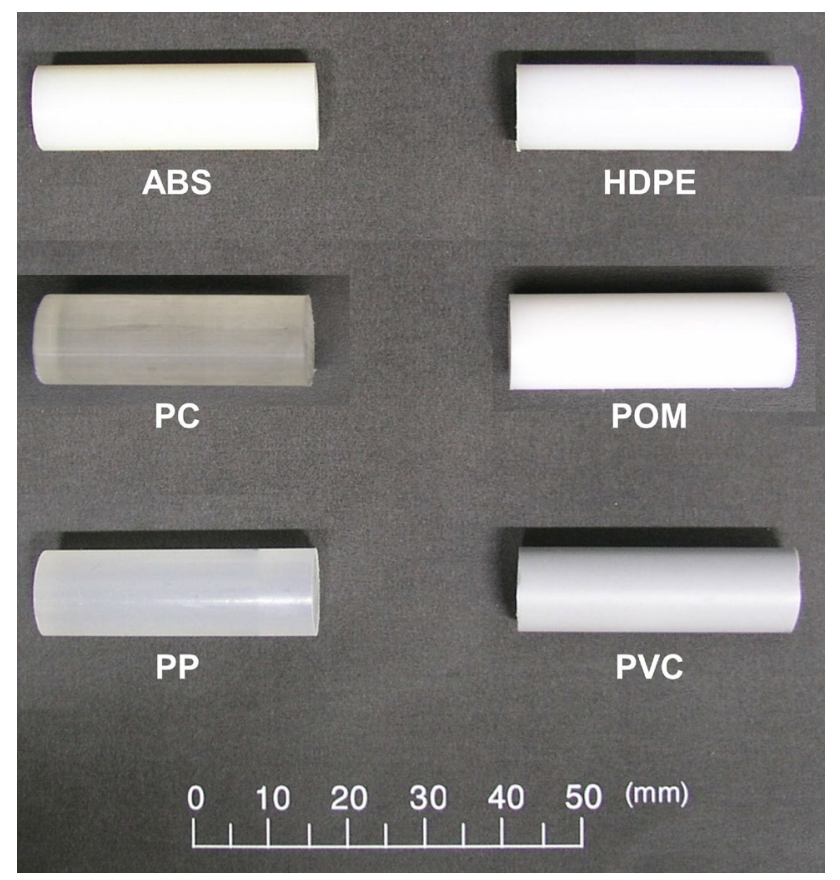

Fig. 1 Photograph of six different extruded polymer rods

Low and Intermediate Strain-Rate Compression Testing

Preliminary compression tests were made using PC specimens with $l / d=1.0$ and 2.0 to examine the effect of slenderness ratio. All specimens were lubricated with a thin layer of petroleum jelly on both end surfaces. This is because Briscoe and Nosker [9], Walley et al. [10], Trautmann et al. [18] and Okereke et al. [25] reported that petroleum jelly provides a lowest sliding friction coefficient between the polymer specimen ends and the Hopkinson bars. Two low strain-rate (nominal) compressive stress-strain loops for PC are compared in Fig. 2, where very little difference is observed between the loops. Low and intermediate strain-rate compression tests were thus conducted using the specimens with $l / d=2.0$ with the Instron testing machine at two different crosshead speeds $V_{\mathrm{c}}$ of $1.3 \mathrm{~mm} \mathrm{~min}^{-1}\left(\dot{\varepsilon}=1.2 \times 10^{-3} \mathrm{~s}^{-1}\right)$ and $130 \mathrm{~mm} \mathrm{~min}^{-1}\left(\dot{\varepsilon}=1.2 \times 10^{-1} \mathrm{~s}^{-1}\right)$. Higher intermediate strain-rate compression tests were further performed using the specimens with $l / d=1.0$ at $V_{\mathrm{c}}=650 \mathrm{~mm} \mathrm{~min}^{-1}$ to achieve the stress-strain loops at $\dot{\varepsilon}=1.2 \mathrm{~s}^{-1}$. The specimens were loaded up to a given strain and unloaded at the same crosshead speed. Compressive stress and strain in the specimens were determined, respectively, using a $100-\mathrm{kN}$ capacity load cell (Instron: Model 2525-801) and an extensometer (Instron: Model 2620-601). Both load and displacement data were recorded at sampling rates of $5 \mathrm{~Hz}$ for $V_{\mathrm{c}}=1.3 \mathrm{~mm} \mathrm{~min}^{-1}$ and $500 \mathrm{~Hz}$ for $V_{\mathrm{c}}=130$ and $650 \mathrm{~mm} \mathrm{m^{-1 }}$.
Table 2 Shape and nominal dimensions of static compression specimens. a $l / d=2.0, \mathbf{b} l / d=1.0$

\begin{tabular}{llll}
\hline Polymer & Length $l(\mathrm{~mm})$ & Diameter $d(\mathrm{~mm})$ & Slenderness ratio $l / d$ \\
\hline
\end{tabular}

(a)

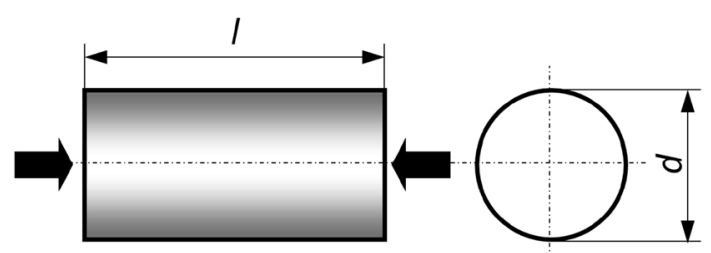

$\begin{array}{lll}\text { ABS } & 17.97 \pm 0.03 & 8.97 \\ \text { HDPE } & 17.97 \pm 0.02 & 8.98 \\ \text { PC } & 18.01 \pm 0.04 & 8.99 \\ \text { POM } & 18.00 \pm 0.01 & 8.99 \\ \text { PP } & 17.97 \pm 0.04 & 8.96 \\ \text { PVC } & 17.94 \pm 0.04 & 8.96\end{array}$

(b)

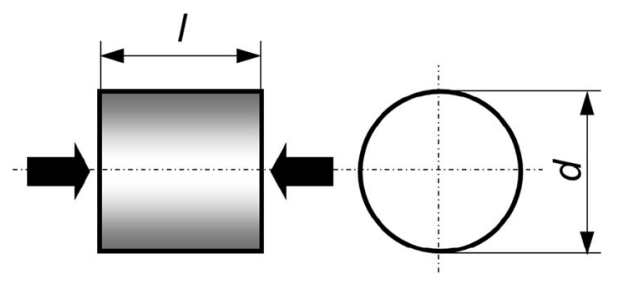

$\begin{array}{llll}\text { ABS } & 8.99 \pm 0.04 & 9.00 & 1.0 \\ \text { HDPE } & 8.98 \pm 0.02 & 8.99 & \\ \text { PC } & 8.99 \pm 0.02 & 8.99 & \\ \text { POM } & 8.99 \pm 0.01 & 9.01 & \\ \text { PP } & 8.99 \pm 0.03 & 8.99 & \\ \text { PVC } & 8.98 \pm 0.02 & 8.99 & \end{array}$

Split Hopkinson Pressure Bar Testing

Figure 3 indicates a schematic of the standard SHPB system used, which consists principally of 2024-T4 Al alloy input and output bars, a 2024-T4 Al alloy striker bar, a gun barrel and an associated recording system (not shown here; see Ref. [58]). The specifications for the SHPB system are listed in Table 4. The $\mathrm{Al}$ alloy bars with low mechanical impedance were used to reduce a drastic impedance mismatch between the polymer specimen $(Z \fallingdotseq$ $1 \sim 2 \times 10^{6} \mathrm{~kg} \mathrm{~m}^{-2} \mathrm{~s}^{-1}$ ) and conventional steel bars $\left(Z \fallingdotseq 40 \times 10^{6} \mathrm{~kg} \mathrm{~m}^{-2} \mathrm{~s}^{-1}\right)$, resulting in a transmitted strain signal with a very low signal-to-noise ratio. The specimen was sandwiched between the input and output bars. As in the low and intermediate strain-rate tests, lubricant (or petroleum jelly) was also applied to the two bar/specimen interfaces to reduce the frictional effects $[9$, $10,18,25]$. A pulse shaping technique [17] was used to generate well-defined compressive strain pulses without 


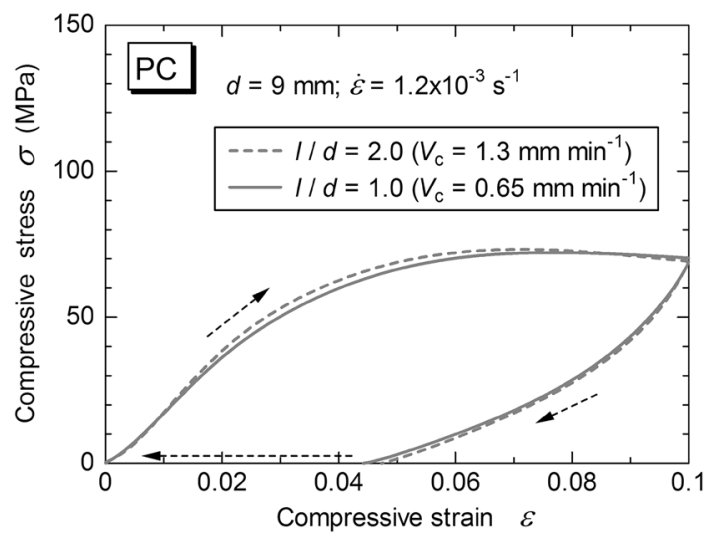

Fig. 2 Effect of specimen geometry on low strain-rate (nominal) compressive stress-strain loops for PC

higher frequency components in the input bar. Namely, a $0.2 \mathrm{~mm}$-thick $1050 \mathrm{Al}$ disk of nearly $10 \mathrm{~mm}$ in diameter was attached onto the impact (left) end of the input bar using a thin layer of petroleum jelly. Details of the test procedure can be found elsewhere [23].

From one-dimensional elastic wave propagation theory, we can determine the nominal strain $\varepsilon(t)$, strain rate $\dot{\varepsilon}(t)$ and stress $\sigma(t)$ in the specimen from the SHPB test records as [59]

$$
\begin{aligned}
& \varepsilon(t)=\frac{u_{1}(t)-u_{2}(t)}{l}=\frac{2 c_{\mathrm{o}}}{l} \int_{0}^{t}\left\{\varepsilon_{i}\left(t^{\prime}\right)-\varepsilon_{t}\left(t^{\prime}\right)\right\} \mathrm{d} t^{\prime} \\
& \dot{\varepsilon}(t)=\frac{\dot{u}_{1}(t)-\dot{u}_{2}(t)}{l}=\frac{2 c_{\mathrm{o}}}{l}\left\{\varepsilon_{i}(t)-\varepsilon_{t}(t)\right\} \\
& \sigma(t)=\frac{P_{2}(t)}{A_{\mathrm{S}}}=\frac{A E}{A_{\mathrm{S}}} \varepsilon_{t}(t)
\end{aligned}
$$

Here $u$ and $P$ are the displacement and the axial force on both ends of the specimen (where subscripts 1 and 2 denote the left and right interfaces, respectively, see an inset in Fig. 3); an overdot denotes the time derivative; $A, E$ and $c_{\mathrm{o}}$ are the cross-sectional area, Young's modulus and the longitudinal elastic wave velocity; $A_{\mathrm{S}}$ is the cross-sectional area of the specimen. Equations (1)-(3) are derived on the assumption of dynamic force equilibrium across the specimen, i.e.,

$P_{1}(t)=P_{2}(t) \quad$ or $\quad \varepsilon_{i}(t)+\varepsilon_{r}(t)=\varepsilon_{t}(t)$

where

$P_{1}(t)=A E\left[\varepsilon_{i}(t)+\varepsilon_{r}(t)\right], \quad P_{2}(t)=A E \varepsilon_{t}(t)$

In the above derivations, the incident and reflected strain pulses are time-shifted to the specimen-input bar interface, and the transmitted strain pulse is time-shifted to the specimen-output bar interface.

In order to derive the constitutive equation, we have to obtain the true stress-true strain curves. Siviour et al. [19], and El-Qoubaa and Othman [27] verified that the total volume of the polymer specimen remains constant during the test. We can thus convert the nominal compressive strain $\varepsilon(t)$, strain rate $\dot{\varepsilon}(t)$ and stress $\sigma(t)$ to the true compressive strain $\bar{\varepsilon}(t)$, strain rate $\dot{\bar{\varepsilon}}(t)$ and stress $\bar{\sigma}(t)$ as

$\bar{\varepsilon}(t)=-\ln [1-\varepsilon(t)]$

$\dot{\bar{\varepsilon}}(t)=\frac{\dot{\varepsilon}(t)}{1-\varepsilon(t)}$

$\bar{\sigma}(t)=\sigma(t)[1-\varepsilon(t)]$

Eliminating time $t$ through Eqs. (5)-(7) yields the true compressive stress-strain and strain rate-strain relations, where compression is taken as positive.

\section{Results and Discussion}

Low Strain-Rate Response

Low strain-rate compressive stress-strain loops up to a strain of nearly 0.10 were determined from the static specimens with $l / d=2.0$. At least, two repeatable tests were made for each polymer. Figure 4 gives typical low

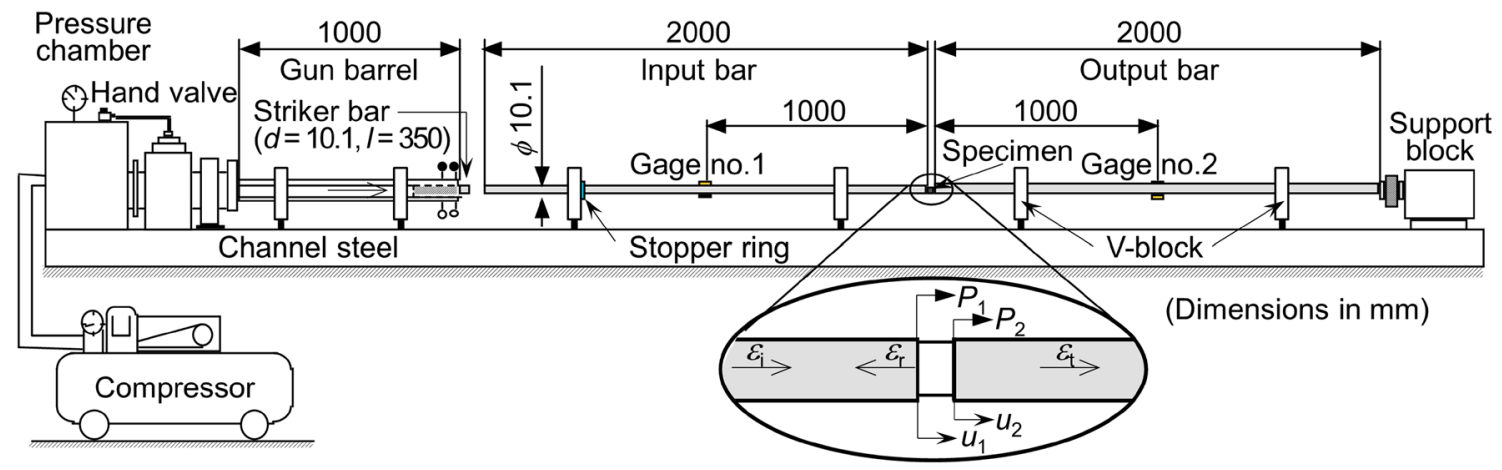

Fig. 3 Schematic of conventional SHPB system (associated recording system not shown) 
Table 3 Shape and nominal dimensions of impact compression specimen

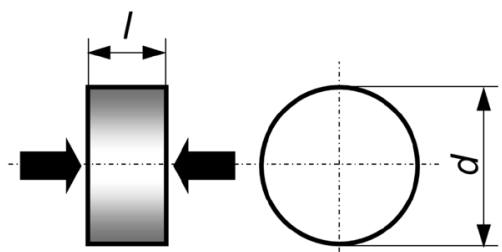

\begin{tabular}{llll}
\hline Polymer & Length $l(\mathrm{~mm})$ & Diameter $d(\mathrm{~mm})$ & Slenderness ratio $l / d$ \\
\hline ABS & $4.44 \pm 0.01$ & 8.98 & 0.5 \\
HDPE & $4.43 \pm 0.03$ & 8.98 & \\
PC & $4.50 \pm 0.02$ & 9.00 & \\
POM & $4.48 \pm 0.02$ & 8.99 & \\
PP & $4.50 \pm 0.07$ & 8.97 & \\
PVC & $4.44 \pm 0.03$ & 8.97 & \\
\hline
\end{tabular}

Table 4 Specifications for present SHPB system

\begin{tabular}{lll}
\hline & Striker bar & $\begin{array}{l}\text { Input/output } \\
\text { bar }\end{array}$ \\
\hline $\begin{array}{l}\text { Material } \\
\text { Young's modulus } E(\mathrm{GPa})\end{array}$ & 73 & \\
Longitudinal wave velocity & 5,134 & $\mathrm{~T} 4 \mathrm{Al}$ alloy \\
$\quad c_{\mathrm{o}}=\sqrt{E / \rho}\left(\mathrm{m} \mathrm{s}^{-1}\right)$ & & \\
Yield strength $\sigma_{\mathrm{Y}}(\mathrm{MPa})$ & 450 & \\
Mass density $\rho\left(\mathrm{kg} \mathrm{m}^{-3}\right)$ & 2,770 & 2,000 \\
Acoustic impedance $Z=\rho c_{\mathrm{o}}$ & $14.2 \times 10^{6}$ \\
$\quad\left(\mathrm{~kg} \mathrm{~m} \mathrm{~m}^{-2} \mathrm{~s}^{-1}\right)$ & 350 & \\
Length $L(\mathrm{~mm})$ & 10.1 & \\
Diameter $d(\mathrm{~mm})$ &
\end{tabular}

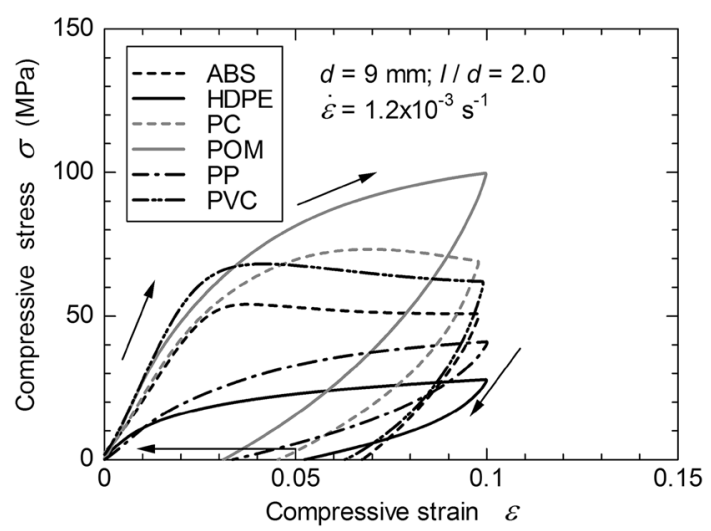

Fig. 4 Typical static (nominal) compressive stress-strain loops for six different polymers

strain-rate (nominal) compressive stress-strain loops for the six different polymers. All stress-strain loops are not closed, and a nonlinear (viscoelastic) unloading process is observed for each specimen. Residual strains following complete unloading are gradually recovered to zero in time, as reported in previous studies [22, 60]. Such behavior is known as an elastic after-effect [61]. The amorphous polymers (ABS, PC and PVC) display a distinct yield phenomenon within a strain of nearly 0.10 , as observed in previous studies [11, 12, 15, 19, 20, 22, 23, 29]. Static compressive and physical properties are given in Table 5. An initial modulus (or apparent elastic modulus) was obtained from the initial slope of each stress-strain curve (as the secant modulus at a strain of 0.005). Measurements of the initial compressive modulus are in general less accurate than those of the initial tensile one. This is entirely due to frictional constraints between the specimen ends and the anvils. We confirmed that the initial compressive moduli were accurately measured through comparison with the initial tensile moduli. The initial compressive moduli in this work and in Refs. $[15,25,62-$ 64] are almost the same for ABS, PC, PP and PVC, but slightly different for HDPE and POM. This difference may be attributed to their different manufacturing processes. The dissipation energy $U_{\mathrm{d}}$ was obtained from the area enclosed by the loop under the stress-strain curve. Note that PVC has the highest initial modulus, proof strength and the largest dissipation energy among all polymers tested.

\section{High Strain-Rate Response}

A number of the SHPB tests were performed on the six different polymers at room temperature. Figure 5 presents typical oscilloscope records of strain gage outputs from the SHPB test on PC. The top trace gives the incident and reflected strain pulses $\left(\varepsilon_{i}\right.$ and $\left.\varepsilon_{r}\right)$, and the bottom trace gives the strain pulse $\left(\varepsilon_{t}\right)$ transmitted through the specimen. The output signals from the strain gages were recorded at a sampling rate of $1 \mathrm{MHz}$. The recorded signal data are neither smoothed nor averaged electronically. Note that the duration $(\fallingdotseq 360 \mu \mathrm{s})$ of the reflected and transmitted strain pulses is much longer than that $(\fallingdotseq 260 \mu \mathrm{s})$ of the incident strain pulse. This is because it takes a long time for the specimen stress to relax to zero [22, 60], causing often overlapping between the transmitted strain pulse and its strain pulse reflected from the free (or right) end of the output bar. In the present SHPB tests, the overlapping of the two strain pulses is successfully avoided by the use of the long output bar. Figure 6 gives the resulting axial stress histories at the front and back ends of the PC specimen, indicating that dynamic stress equilibrium is achieved in the specimen over the entire loading duration. Figure 7 shows the resulting dynamic true compressive stress-strain loop and strain rate-strain relation for PC. The true strain rate varies its sign from compression (+) to tension $(-)$ at a maximum loading strain. The true strain rate does not 
Table 5 Static compressive and physical properties of six different polymers tested

\begin{tabular}{llllllll}
\hline Polymer & $\begin{array}{l}\text { Initial } \\
\text { modulus }^{\mathrm{a}} \\
E(\mathrm{GPa})\end{array}$ & $\begin{array}{l}\text { Proof strength } \\
\sigma_{0.2}(\mathrm{MPa})\end{array}$ & $\begin{array}{l}\text { Compressive } \\
\text { strength } \sigma_{\mathrm{C}} \\
(\mathrm{MPa})\end{array}$ & $\begin{array}{l}\text { Dissipation energy } U_{\mathrm{d}} \\
\left(\mathrm{MJ} \mathrm{m}^{-3}\right) \text { up to } \varepsilon=0.10\end{array}$ & $\begin{array}{l}\text { Glass transition } \\
\text { temperature } T_{\mathrm{g}}\left({ }^{\circ} \mathrm{C}\right)\end{array}$ & $\begin{array}{l}\text { Mass density } \\
\rho\left(\mathrm{kg} \mathrm{m} \mathrm{m}^{-3}\right)\end{array}$ & $\begin{array}{l}\text { Melting } \\
\text { point } T_{\mathrm{m}} \\
\left({ }^{\circ} \mathrm{C}\right)^{\mathrm{d}}\end{array}$ \\
\hline ABS & $2.1(1.8-2.8)^{\mathrm{b}}$ & 48.0 & $54.1(52)^{\mathrm{h}}$ & 3.81 & $(105)^{\mathrm{h}}$ & 1040 & N/A \\
HDPE & $1.7(0.5-1.4)^{\mathrm{b}}$ & 12.0 & N/A $(25)^{\mathrm{h}}$ & 1.63 & $(15)^{\mathrm{h}}$ & 960 & 131 \\
PC & $2.2(2.4)^{\mathrm{e}}$ & 47.5 & $73.3(76)^{\mathrm{h}}$ & 4.37 & $(-60)^{\mathrm{h}}$ & 1200 & 1410 \\
POM & $2.9(3.8)^{\mathrm{f}}$ & 46.3 & N/A $(107)^{\mathrm{h}}$ & 4.59 & $(-10)^{\mathrm{h}}$ & 900 & 164 \\
PP & $1.2(1.3)^{\mathrm{g}}$ & 16.7 & N/A $(55)^{\mathrm{h}}$ & 1.94 & $(80)^{\mathrm{h}}$ & 1420 \\
PVC & $3.0(3.3)^{\mathrm{c}}$ & 56.7 & $68.2(72)^{\mathrm{h}}$ & 4.90 & N/A \\
\hline
\end{tabular}

${ }^{a}$ Defined as secant modulus at 0.005 strain, except for HDPE and PP whose secant modulus at 0.002 strain

b Values in parentheses indicate initial tensile modulus taken from Ref. [62]

${ }^{c}$ Values in parentheses indicate initial tensile modulus taken from textbook [63]

d Measured by thermogravimetry differential thermal analyzer (TG-DTA: Rigaku Thermo Plus TG 8120)

e Taken from Ref. [15]

f Taken from Ref. [64]

g Taken from Ref. [25]

${ }^{\mathrm{h}}$ Values in parentheses are provided by suppliers

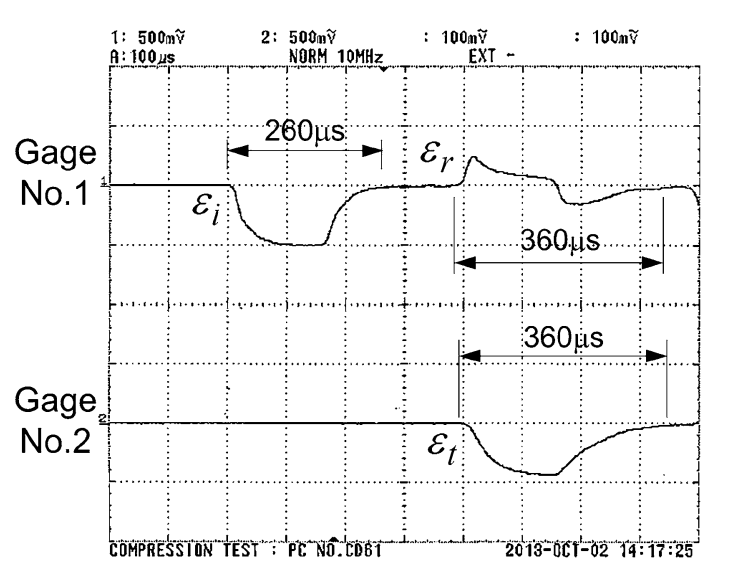

Sweep rate: $100 \mu \mathrm{s} / \mathrm{div}$

Vertical sensitivity:

Upper trace: $500 \mathrm{mV} / \mathrm{div}(1252 \mu \varepsilon / \mathrm{div})$

Lower trace: $500 \mathrm{mV} / \mathrm{div}(1248 \mu \varepsilon / \mathrm{div})$

Fig. 5 Oscilloscope traces of strain gage outputs from SHPB test on $\mathrm{PC}\left(V_{\mathrm{S}}=12.3 \mathrm{~m} \mathrm{~s}^{-1}\right)$

remain constant during loading or unloading; hence, the true strain rate $\dot{\bar{\varepsilon}}=670 \mathrm{~s}^{-1}$ given indicates the average one during loading. As in the low and intermediate strain-rate tests, the dynamic stress-strain loop is not closed, and a residual strain of about 0.006 is gradually recovered to zero in time (i.e., elastic after-effect). Figure 8 shows typical true compressive stress-strain loops for PC at four different strain rates. All stress-strain curves exhibit similar characteristics: a nearly linear behavior at small strains followed by a nonlinear one is observed during both loading

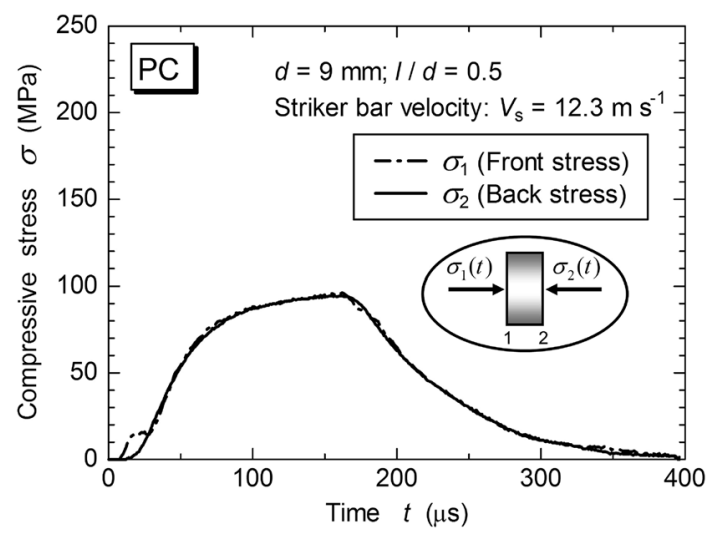

Fig. 6 Comparison of stress histories at front and back ends of PC specimen

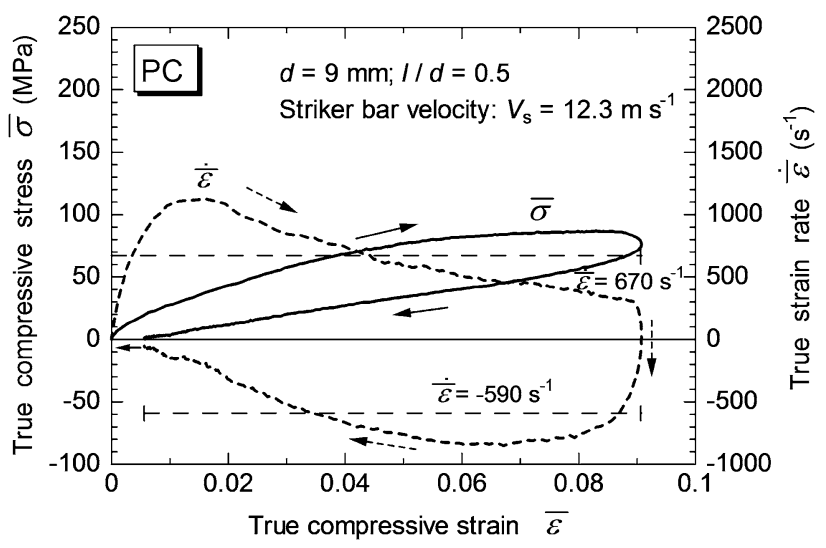

Fig. 7 Dynamic true compressive stress-strain loop and strain ratestrain relation for $\mathrm{PC}$ 


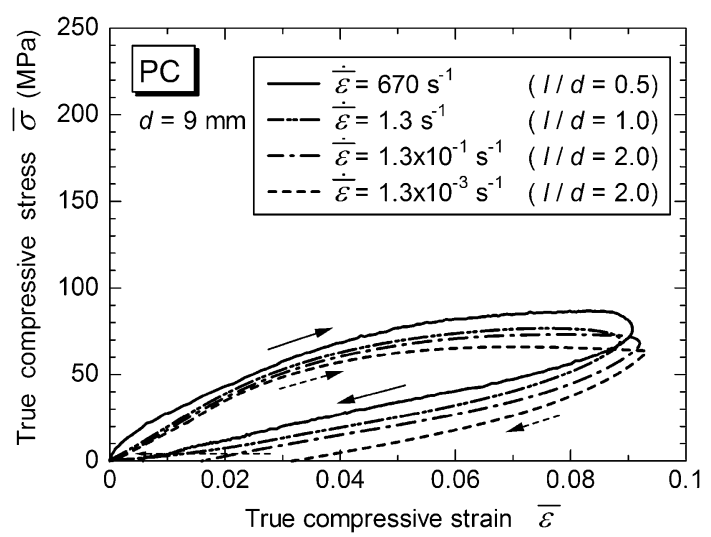

Fig. 8 Typical true compressive stress-strain loops for PC at four different strain rates

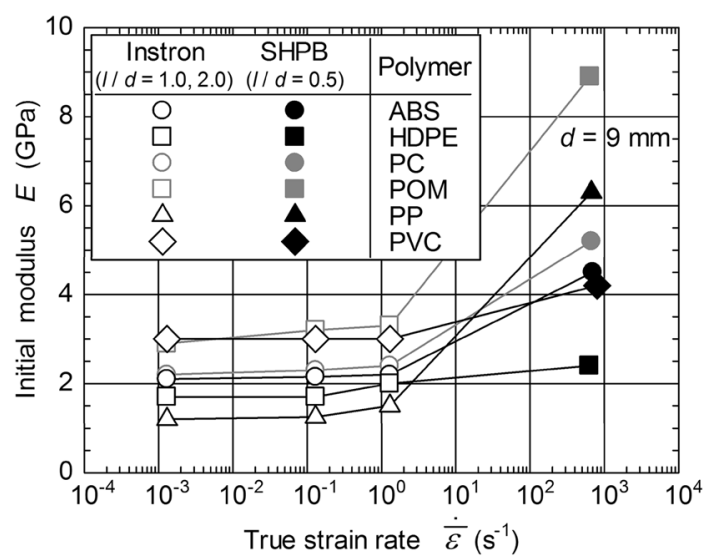

Fig. 9 Effect of true strain rate on initial modulus for six different polymers

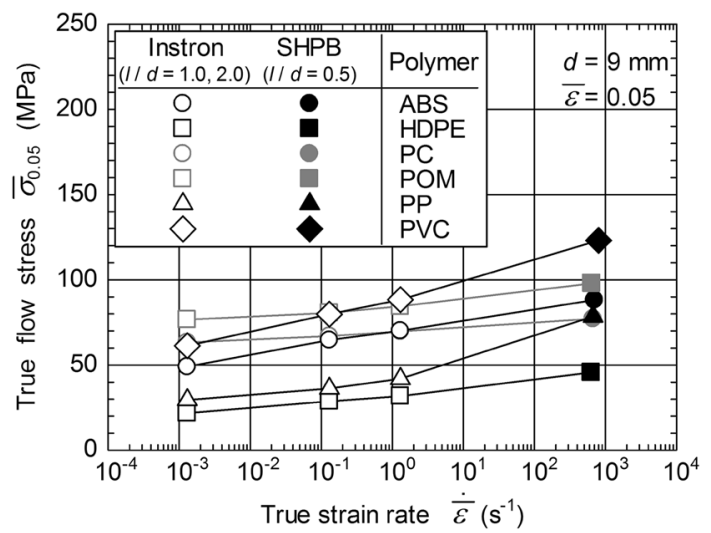

Fig. 10 Effect of true strain rate on true flow stress at true strain of 0.05 for six different polymers

and unloading processes. The initial modulus (elastic modulus) $E$ and the flow stress increase appreciably with increasing strain rate. The respective nonlinear unloading stress-strain curves indicate the dynamic viscoelastic behavior of PC. Each residual strain is found to depend on both stress and strain rate levels, not the maximum loading strain. A higher strain rate leads to a smaller residual strain. A possible reason for this behavior will be discussed later.

The measured values for the initial modulus and true flow stress for all polymers at a given true strain of 0.05 are plotted in Figs. 9 and 10, respectively, against the average true strain rate $\dot{\bar{\varepsilon}}$ during loading. At least, three SHPB tests were conducted at nearly similar strain rates and variations in the flow stress from test to test were negligible for each polymer. The initial modulus $E$ is defined herein as the slope (or secant modulus) of the line connecting the origin to the stress at a strain of 0.002 . This is because the dynamic stress equilibrium in the specimen becomes valid beyond its strain for all polymers. The initial modulus $E$ and true flow stress at a true strain of 0.05 for all polymers increase significantly with increasing strain rate, except for HDPE, which suggests the dynamic viscoelastic-plastic behavior.

To quantify the rate dependence of the flow stresses, we introduce two different strain-rate sensitivity parameters $\beta$ and $m$ [65] (see two definitions in Table 6). The parameter values estimated for all polymers are summarized in Table 6 , where $\bar{\sigma}_{1}$ and $\bar{\sigma}_{2}$ are the respective true flow stresses at two average true strain rates $\dot{\bar{\varepsilon}}_{1}$ and $\dot{\bar{\varepsilon}}_{2}$ for a fixed true strain of 0.05 . The choice of 0.05 strain was made between the common strains at strain rates, corresponding approximately to the respective average strain rates during loading. PVC displays the highest rate dependence with respect to $\beta$, and PP exhibits the highest one with respect to $m$. PC shows the lowest one with respect to $\beta$ and $m$. Walley and Field [12] estimated the strain-rate sensitivity parameter $\beta$ of the flow stress at a larger strain of 0.20 for various polymers. A good correlation can be observed in the parameter $\beta$ between this work and Ref. [12], except for PC. There is a large difference in the parameter $\beta$ for PC between the flow stresses at 0.05 and 0.20 strains. The rate dependence of the flow stresses for PC on applied strain was also examined in other studies $[11,15,19,20,22,29]$. There is less effect of strain rate on the flow stresses for PC at smaller strains before yielding. At larger strains after yielding in PC, the strain softening at low strain rates is much more significant than that at high strain rates; therefore, this results in a marked difference in the flow stresses for a larger strain of 0.20 at low and high strain rates.

\section{Constitutive Modeling}

To characterize the true compressive stress-strain behavior of all polymers, we attempt to apply the Ramberg-Osgood power law [66], i.e., 
Table 6 Values of two strain-rate sensitivity parameters $(\beta, m)$ for six different polymers over a wide range of true strain rates from $\dot{\bar{\varepsilon}}_{1}=1.2 \times 10^{-3} \mathrm{~s}^{-1}$ to $\dot{\overline{\varepsilon_{2}}} \fallingdotseq 840 \mathrm{~s}^{-1}$

\begin{tabular}{|c|c|c|}
\hline Polymer & $\begin{array}{l}\beta=\left.\frac{\bar{\sigma}_{2}-\bar{\sigma}_{1}}{\log \left(\overline{\bar{\varepsilon}}_{2} / \overline{\bar{\varepsilon}}_{1}\right)}\right|_{\bar{\varepsilon}=0.05} \\
(\mathrm{MPa}) \overline{\bar{\varepsilon}}_{2}>\overline{\bar{\varepsilon}}_{1}\end{array}$ & $\begin{array}{l}m=\left.\frac{\log \left(\overline{\bar{\sigma}}_{2} / \bar{\sigma}_{1}\right)}{\log \left(\overline{\bar{\varepsilon}}_{2} / \overline{\bar{\varepsilon}}_{1}\right)}\right|_{\bar{\varepsilon}=0.05} \\
(-) \dot{\bar{\varepsilon}}_{2}>\overline{\bar{\varepsilon}}_{1}\end{array}$ \\
\hline \multicolumn{3}{|c|}{ Amorphous } \\
\hline ABS & $2.90(2.31)^{\mathrm{a}}$ & 0.044 \\
\hline $\mathrm{PC}$ & $1.03(2.97)$ & 0.015 \\
\hline PVC & $4.52(4.84)$ & 0.051 \\
\hline \multicolumn{3}{|c|}{ Semi-crystalline } \\
\hline HDPE & $1.81(1.90)$ & 0.056 \\
\hline POM & $1.58(-)^{\mathrm{b}}$ & 0.018 \\
\hline PP & $3.64(3.91)$ & 0.073 \\
\hline
\end{tabular}

${ }^{\mathrm{a}}$ Values in parentheses are taken from Ref. [12] $(\varepsilon=0.20)$

b No data are available in Ref. [12]

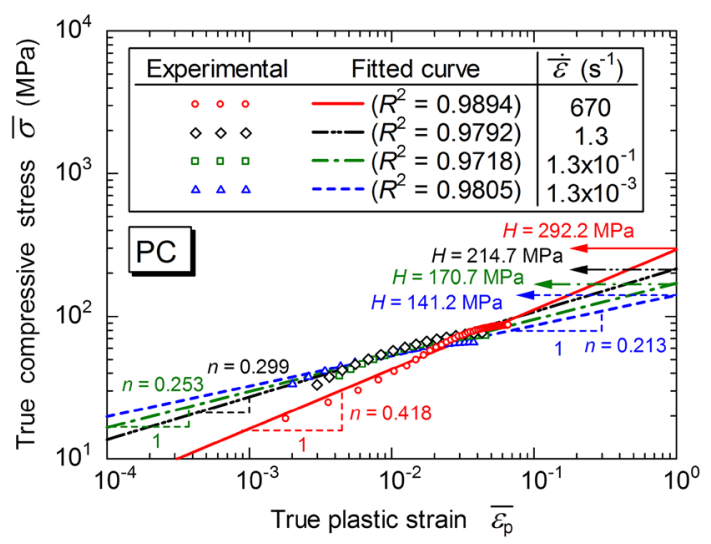

Fig. 11 Determination of constants $H$ and $n$ for PC at four different strain rates by linear least-squares fit

$\bar{\varepsilon}(\bar{\sigma})=\frac{\bar{\sigma}}{E}+\left(\frac{\bar{\sigma}}{H}\right)^{\frac{1}{n}}$

where $E$ is the initial (or elastic) modulus, $H$ the strength coefficient and $n$ the strain-hardening exponent (or coefficient). The first and second terms on the right-hand side of Eq. (8) correspond to the true elastic strain $\bar{\varepsilon}_{\mathrm{e}}$ and the true plastic strain $\bar{\varepsilon}_{\mathrm{p}}$, respectively. From Eq. (8), we can obtain

$\bar{\sigma}\left(\bar{\varepsilon}_{\mathrm{p}}\right)=H \bar{\varepsilon}_{\mathrm{p}}^{n}=H\left(\bar{\varepsilon}-\frac{\bar{\sigma}}{E}\right)^{n}$

Taking logarithms of both sides of Eq. (9) yields

$\log \bar{\sigma}=\log H+n \log \bar{\varepsilon}_{\mathrm{p}}$

Figure 11 gives typical log-log plots of the true stress $\bar{\sigma}$-true plastic strain $\bar{\varepsilon}_{\mathrm{p}}$ for PC at four different strain rates obtained from Fig. 8. The two constants $H$ and $n$ were determined by fitting the measured data points on the

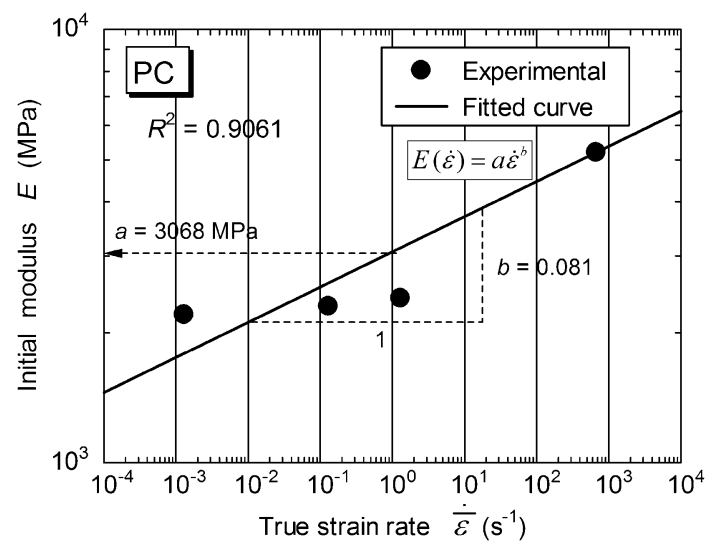

Fig. 12 Initial modulus $E$ as function of true strain rate $\dot{\bar{\varepsilon}}$ for PC. Determination of parameters $a$ and $b$ by linear least-squares fit

$\bar{\sigma}-\bar{\varepsilon}_{\mathrm{p}}$ curves to Eq. (10) using a linear least-squares technique. The total number of the data points used was nearly 180 for low and intermediate strain-rate tests, and nearly 150 for high strain-rate tests. The constant $H$ corresponds to the value of $\bar{\sigma}$ at $\bar{\varepsilon}_{\mathrm{p}}=1$. The constant $n$ was obtained from the slope of a linear fit line. A value of $R^{2}$ (coefficient of determination) indicates a measure of the goodness of fit to Eq. (10). Figure 11 suggests also that both $H$ and $n$ depend on the true strain rate $\dot{\bar{\varepsilon}}$ alone. Therefore, $E, H$ and $n$ are, respectively, assumed to be represented by simple power law functions of $\dot{\bar{\varepsilon}}$ as

$E(\dot{\bar{\varepsilon}})=a \dot{\dot{\varepsilon}^{b}}$

$H(\dot{\bar{\varepsilon}})=c \dot{\bar{\varepsilon}}^{d}$

$n(\dot{\bar{\varepsilon}})=p \dot{\bar{\varepsilon}}^{q}$

where $a, b, c, d, p$ and $q$ are material parameters. Again taking logarithms of both sides of Eqs. (11)-(13) leads to

$\log E=\log a+b \log \dot{\bar{\varepsilon}}$

$\log H=\log c+d \log \dot{\bar{\varepsilon}}$

$\log n=\log p+q \log \dot{\bar{\varepsilon}}$

Substituting Eqs. (11)-(13) into Eq. (8) yields the modified rate-dependent Ramberg-Osgood equation [26, $67,68]$ as

$\bar{\varepsilon}(\bar{\sigma}, \dot{\bar{\varepsilon}})=\frac{\bar{\sigma}}{a \dot{\bar{\varepsilon} b}}+\left(\frac{\bar{\sigma}}{c \dot{\bar{\varepsilon} d}}\right)^{\frac{1}{p \dot{\bar{\varepsilon} q}}}$

The values of $E, H$ and $n$ for PC are plotted in Figs. 12, 13 and 14, respectively, against the average true strain rate $\dot{\bar{\varepsilon}}$ during loading. The six parameters $a, b, c, d, p$ and $q$ were determined by fitting four sets of measured data points (solid symbols) to Eqs. (14)-(16) using the linear leastsquares technique. The fitted curves are shown as the solid lines in the respective figures. The parameters in Eq. (17) 


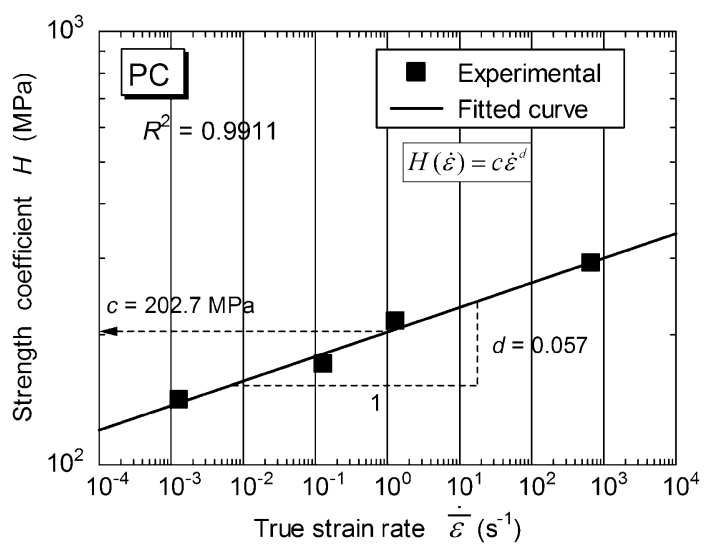

Fig. 13 Strength coefficient $H$ as function of true strain rate $\dot{\bar{\varepsilon}}$ for PC. Determination of parameters $c$ and $d$ by linear least-squares fit

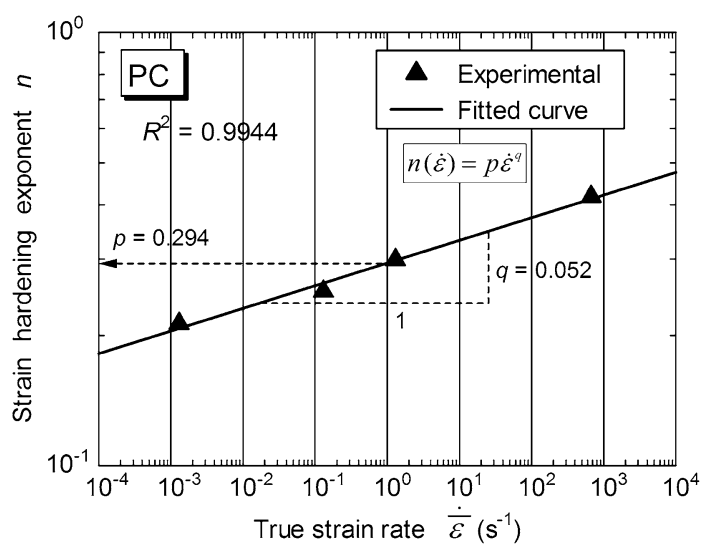

Fig. 14 Strain-hardening exponent $n$ as function of true strain rate $\dot{\bar{\varepsilon}}$ for PC. Determination of parameters $p$ and $q$ by linear least-squares fit

obtained for all polymers are summarized in Table 7. All values of $R_{2}^{2}$ and $R_{3}^{2}$ are very close to 1 , indicating that the values of $H$ and $n$ for all polymers were accurately determined by the linear least-squares fits. In contrast, $R_{1}^{2}$ values for $E$ are less than at most 0.938 . Figure 12 shows that the initial modulus $E$ (see the solid circles) increases abruptly at strain rates of over $10^{0} \mathrm{~s}^{-1}$ for PC. Therefore, it is at present very difficult to exactly describe this behavior by the linear power law model. Note in Table 7 that the strainhardening exponent $n$ is independent of applied strain rate for the semi-crystalline polymers (HDPE, POM and PP). The values of $n$ for the polymers are strongly affected by their molecular structure parameters: molecular weight $[69$, 70], crystallinity [31, 42, 71, 72], molecular entanglement density [73] and molecular chain length [73, 74]. The parameters $a$ and $b$ are associated with the effect of strain rate on the initial modulus, while the remaining parameters $c, d, p$ and $q$ are associated with that on the plastic flow. When the strain-hardening exponent $n$ is independent of applied strain rate (or $q=0$ ), we have

$$
\left(\frac{\bar{\sigma}_{1}}{c \dot{\bar{\varepsilon}}_{1}}\right)^{\frac{1}{p}}=\left(\frac{\bar{\sigma}_{2}}{c \dot{\bar{\varepsilon}}_{2}^{d}}\right)^{\frac{1}{p}} \text { or }\left(\frac{\bar{\sigma}_{2}}{\bar{\sigma}_{1}}\right)=\left(\frac{\dot{\bar{\varepsilon}}_{2}}{\dot{\bar{\varepsilon}}_{1}}\right)^{d}
$$

for a given value of $\bar{\varepsilon}_{\mathrm{p}}$ from the second term on the righthand side of Eq. (17). Here $\bar{\sigma}_{1}$ and $\bar{\sigma}_{2}$ are the respective true flow stresses at two different true strain rates $\dot{\bar{\varepsilon}}_{1}$ and $\dot{\bar{\varepsilon}}_{2}$ $\left(\dot{\bar{\varepsilon}}_{2}>\dot{\bar{\varepsilon}}_{1}\right)$ for each of the semi-crystalline polymers involved. Equation (18) implies that the increase in the flow stresses with increasing strain rate is indicated only by the parameter $d$. Hence, for the semi-crystalline polymers (HDPE, POM and PP), a close correlation can be observed between the strain-rate sensitivity parameter $m$ in Table 6 and the parameter $d$ in Table 7 .

Figure 15 shows comparisons between the measured true stress-strain loops and the model predictions at four different strain rates for all polymers. Overall, the present modified Ramberg-Osgood model gives better agreement with the experimental loading stress-strain data than a simplified version of the modified Ramberg-Osgood one [26] with a constant strain-hardening exponent $n$. For the semi-crystalline polymers (HDPE, POM and PP), the loading stress-strain curves at strain rates from $10^{-3}$ to nearly $10^{3} \mathrm{~s}^{-1}$ can accurately be predicted by the modified Ramberg-Osgood equation, up to a maximum strain $(\varepsilon \fallingdotseq 0.08)$. However, for POM and PP, there is a slight discrepancy between measured and predicted stress-strain
Table 7 Parameter values for modified rate-dependent Ramberg-Osgood equation for six different polymers

$\bar{\varepsilon}(\bar{\sigma}, \dot{\bar{\varepsilon}})=\frac{\bar{\sigma}}{E(\overline{\bar{\varepsilon}})}+\left(\frac{\bar{\sigma}}{H(\bar{\varepsilon})}\right)^{\frac{1}{n(\bar{\varepsilon})}}$

${ }^{\text {a }} R_{1}^{2}, R_{2}^{2}$ and $R_{3}^{2}$ (coefficient of determination) values indicate measure of goodness of fit to Eqs. (14)-(16), respectively

\begin{tabular}{|c|c|c|c|c|c|c|c|c|c|}
\hline \multirow[t]{2}{*}{ Polymer } & \multicolumn{3}{|c|}{$E(\dot{\bar{\varepsilon}})=a \dot{\vec{\varepsilon}} b$} & \multicolumn{3}{|c|}{$H(\dot{\bar{\varepsilon}})=c \dot{\bar{\varepsilon}}^{d}$} & \multicolumn{3}{|c|}{$n(\dot{\bar{\varepsilon}})=p \dot{\bar{\varepsilon}}^{q}$} \\
\hline & $a(\mathrm{MPa})$ & $b(-)$ & $R_{1}^{2 \mathrm{a}}$ & $c(\mathrm{MPa})$ & $d(-)$ & $R_{2}^{2 \mathrm{a}}$ & $p(-)$ & $q(-)$ & $R_{3}^{2 \mathrm{a}}$ \\
\hline \multicolumn{10}{|c|}{ Amorphous } \\
\hline ABS & 2795 & 0.073 & 0.8950 & 118.8 & 0.064 & 0.9799 & 0.120 & 0.083 & 0.9804 \\
\hline PC & 3068 & 0.081 & 0.9061 & 202.7 & 0.057 & 0.9911 & 0.294 & 0.052 & 0.9944 \\
\hline PVC & 3307 & 0.036 & 0.8796 & 161.7 & 0.082 & 0.9996 & 0.142 & 0.074 & 0.9965 \\
\hline \multicolumn{10}{|c|}{ Semi-crystalline } \\
\hline HDPE & 1957 & 0.028 & 0.9375 & 62.6 & 0.058 & 0.9986 & 0.204 & 0 & - \\
\hline POM & 4574 & 0.103 & 0.9024 & 272.3 & 0.005 & 0.9710 & 0.333 & 0 & - \\
\hline PP & 2276 & 0.156 & 0.9115 & 112.2 & 0.068 & 0.9910 & 0.257 & 0 & - \\
\hline
\end{tabular}



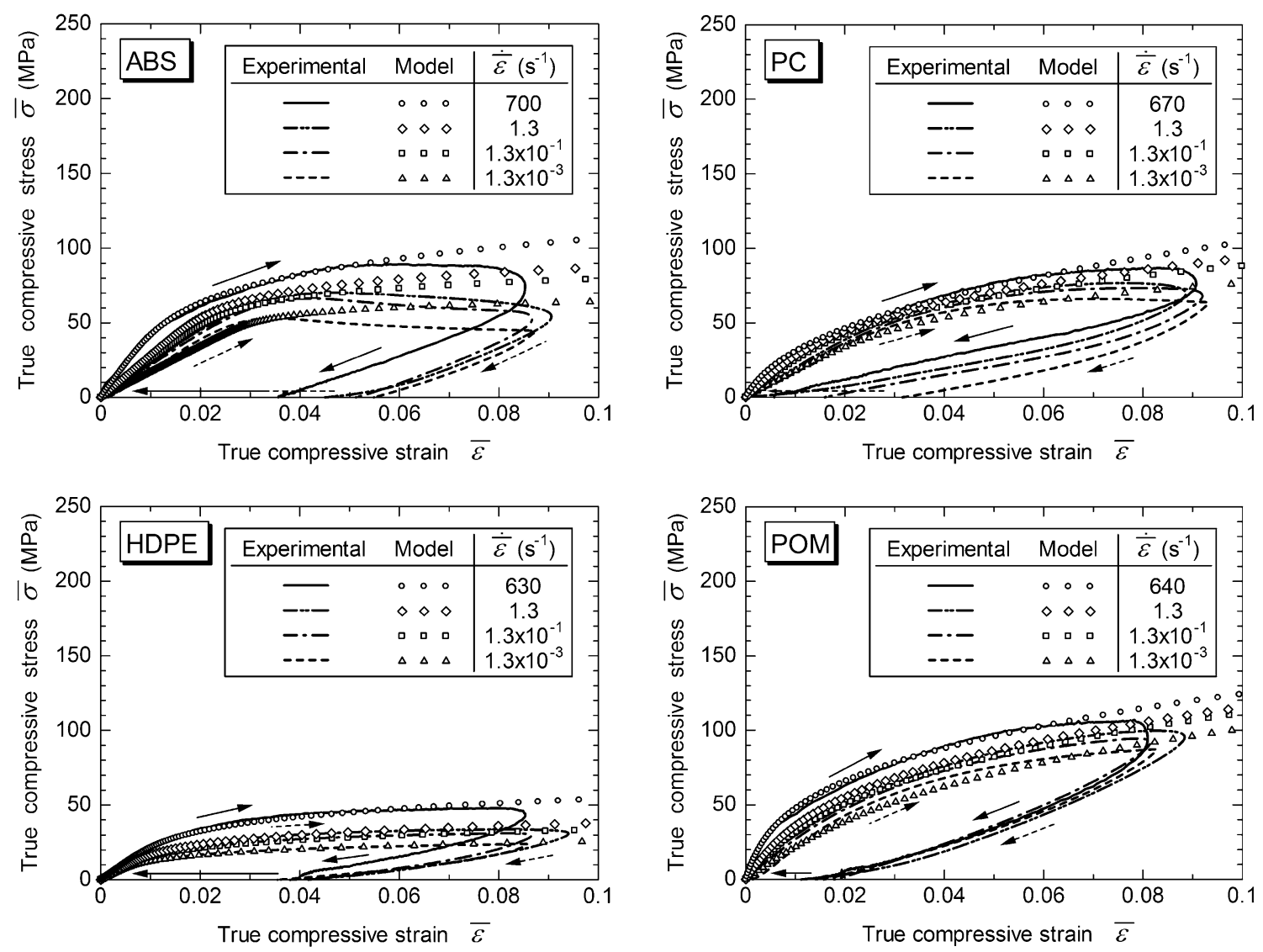

Fig. 15 Comparisons between experimental true compressive stress-strain loops and model predictions at four different strain rates for six different polymers

curves in the initial elastic region at low and intermediate strain rates. To reduce this discrepancy, we have to further consider the rate dependence of the initial modulus using nonlinear models. For the amorphous polymers (ABS, PC and PVC), the predicted stress-strain curves start to deviate from the experimental curves beyond a strain of approximately 0.05 . This is because the amorphous polymers exhibit intrinsic strain softening followed by hardening phenomena [20, 29, 52-54] after yielding, independently of the strain rate. This characteristic behavior cannot reasonably be described by the modified Ramberg-Osgood relation. The strain softening is induced by chains slippage, whereas the strain hardening is caused by alignment and extension of chains in the loading direction [54, 64, 75]. At higher strain rates, amorphous polymers reveal the intrinsic strain softening and thermal softening [7, 15, 20, 22, 29, 54] due to adiabatic heating after yielding. Mulliken and Boyce [20], Porter and Gould [51], and Richeton et al. [54] argued that it is possible to capture the strain softening followed by hardening behavior of amorphous polymers over a wide range of strain rates and temperatures using extended constitutive relations including molecular structure parameters and adiabatic parameters. Figure 15 suggests also that the unloading stress-strain curves at any strain rate for all polymers cannot be predicted by the modified Ramberg-Osgood equation. The residual strain after complete unloading decreases with increasing strain rate, although the maximum loading strain is almost the same $\left(\varepsilon_{\max } \fallingdotseq 0.08\right)$ for the amorphous polymers (ABS, PC and PVC). This result is quite consistent with other compression data on an amorphous polymer (PMMA) by Song and Chen [17]. Meanwhile, the residual strain is independent of strain rate for the semi-crystalline polymers (HDPE, POM and PP). This different unloading stressstrain behavior may arise from differences in the molecular structures between the amorphous and semi-crystalline polymers. In an effort to express the high strain-rate unloading stress-strain relations for the polymers, we need to further develop a rate-dependent constitutive model based on their molecular structures [20, 49, 51, 54].

Finally, we mention the advantages and limitations of the modified rate-dependent Ramberg-Osgood constitutive model or Eq. (17). The simple constitutive model with six parameters can represent complicated dynamic viscoelastic-plastic characteristics of polymers. A closed-form of the stress in terms of the strain and strain rate cannot 

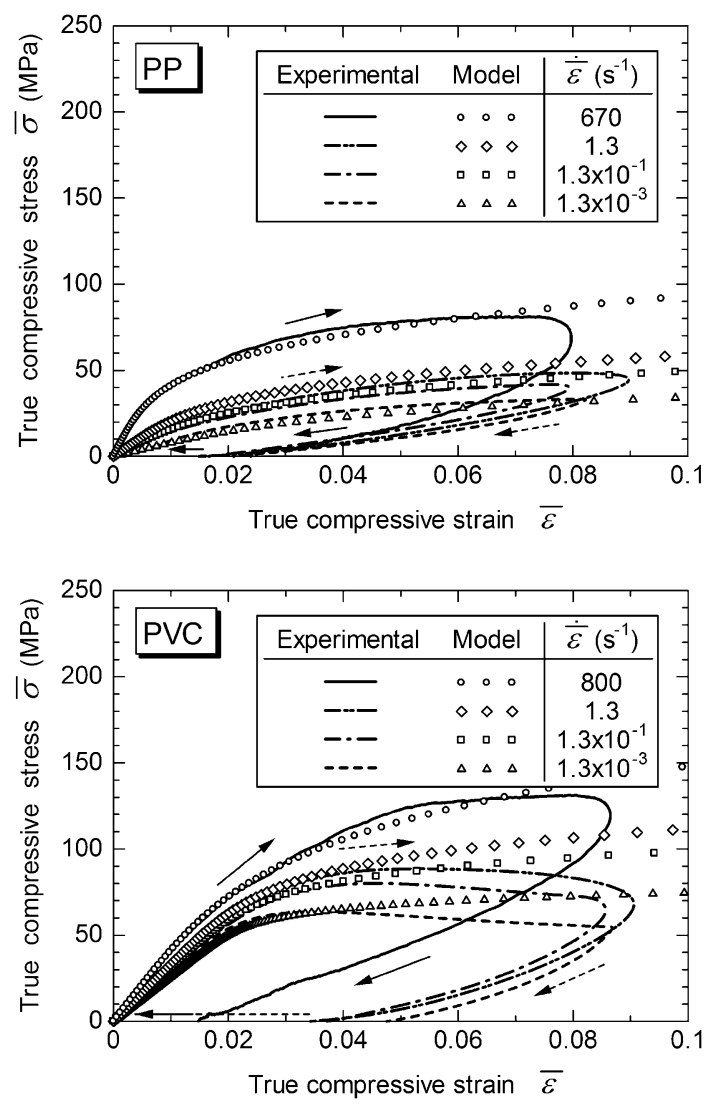

Fig. 15 continued

directly be derived from Eq. (17). The applicability of the simple constitutive model is limited within a strain of nearly 0.05 , especially, for the three amorphous polymers (ABS, PC and PVC). Nevertheless, we can assert that the simple model is valid for conducting numerical simulations of the mechanical response of polymers at strain rates up to approximately $10^{3} \mathrm{~s}^{-1}$ within a limited strain region.

\section{Conclusions}

The rate dependence of uniaxial compressive stress-strain loops for the six commercial polymers has been investigated using the standard SHPB and the Instron testing machine. The modified rate-dependent Ramberg-Osgood model was developed and its advantages and limitations were discussed. From the present experimental work, we can conclude the following:

(1) All polymers exhibit intrinsic dynamic viscoelasticplastic behavior and a higher elastic after-effect following complete unloading.

(2) The initial modulus and flow stresses for all polymers increase appreciably with increasing strain rate, except for HDPE.
(3) For the semi-crystalline polymers (HDPE, POM and PP), the loading compressive stress-strain curves at strain rates from $10^{-3}$ to nearly $10^{3} \mathrm{~s}^{-1}$ can successfully be represented by the modified RambergOsgood equation.

(4) For the amorphous polymers (ABS, PC and PVC), the loading compressive stress-strain curves up to a strain of nearly 0.05 at strain rates from $10^{-3}$ to nearly $10^{3} \mathrm{~s}^{-1}$ can be expressed in terms of the modified Ramberg-Osgood equation, except for the strain softening after yielding regime.

(5) The modified Ramberg-Osgood equation cannot be applied to model the unloading compressive stressstrain behavior at low or high strain rates.

The polymers are known to reveal different mechanical characteristics in tension and compression. Further work is needed for constitutive modeling of the tensile behavior of the six polymers over a broad range of strain rates and temperatures.

Acknowledgments This work was supported in part by a Grant-inAid for Scientific Research (C) (No. 22560686) from the Japan Society for Promotion of Science. The authors wish to thank two reviewers for their helpful comments and suggestions.

\section{References}

1. Wada Y, Kasahara T (1967) Relation between impact strength and dynamic mechanical properties of plastics. J Appl Polym Sci 11:1661-1665

2. Brown HR (1973) A critical examination of the impact test for glassy polymers. J Mater Sci 8:941-948

3. Allen G, Morley DCW, Williams T (1973) The impact strength of polycarbonate. J Mater Sci 8:1449-1452

4. Oshinski AJ, Keskkula H, Paul DR (1996) The role of matrix molecular weight in rubber toughened nylon 6 blends: 2. room temperature Izod impact toughness. Polymer 37:4909-4918

5. Davies EDH, Hunter SC (1963) The dynamic compression testing of solids by the method of the split Hopkinson pressure bar. J Mech Phys Solids 11:155-179

6. Chiu SS, Neubert VH (1967) Difference method for wave analysis of the split Hopkinson pressure bar with a viscoelastic specimen. J Mech Phys Solids 15:177-193

7. Chou SC, Robertson KD, Rainey JH (1973) The effect of strain rate and heat developed during deformation on the stress-strain curve of plastics. Exp Mech 13:422-432

8. Chase KW, Goldsmith W (1974) Mechanical and optical characterization of an anelastic polymer at large strain rates and large strains. Exp Mech 14:10-18

9. Briscoe BJ, Nosker RW (1984) The influence of interfacial friction on the deformation of high density polyethylene in a split Hopkinson pressure bar. Wear 95:241-262

10. Walley SM, Field JE, Pope PH, Safford NA (1989) A study of the rapid deformation behaviour of a range of polymers. Philos Trans R Soc Lond A 328:1-33

11. Dioh NN, Leevers PS, Williams JG (1993) Thickness effects in split Hopkinson pressure bar tests. Polymer 34:4230-4234

12. Walley SM, Field JE (1994) Strain rate sensitivity of polymers in compression from low to high rates. DYMAT J 1:211-227 
13. Tay TE, Ang HG, Shim VPW (1995) An empirical strain ratedependent constitutive relationship for glass-fibre reinforced epoxy and pure epoxy. Compos Struct 33:201-210

14. Buckley CP, Harding J, Hou JP, Ruiz C, Trojanowski A (2001) Deformation of thermosetting resins at impact rates of strain. Part I: experimental study. J Mech Phys Solids 49:1517-1538

15. Li Z, Lambros J (2001) Strain rate effects on the thermomechanical behavior of polymers. Int J Solid Struct 38:3549-3562

16. Chen W, Lu F, Cheng M (2002) Tension and compression tests of two polymers under quasi-static and dynamic loading. Polym Test 21:113-121

17. Song B, Chen W (2004) Loading and unloading split Hopkinson pressure bar pulse-shaping techniques for dynamic hysteretic loops. Exp Mech 44:622-627

18. Trautmann A, Siviour CR, Walley SM, Field JE (2005) Lubrication of polycarbonate at cryogenic temperatures in the split Hopkinson pressure bar. Int J Impact Eng 31:523-544

19. Siviour CR, Walley SM, Proud WG, Field JE (2005) The high strain rate compressive behaviour of polycarbonate and polyvinylidene difluoride. Polymer 46:12546-12555

20. Mulliken AD, Boyce MC (2006) Mechanics of the rate-dependent elastic-plastic deformation of glassy polymers from low to high strain rates. Int J Solid Struct 43:1331-1356

21. Jordan JL, Siviour CR, Foley JR, Brown EN (2007) Compressive properties of extruded polytetrafluoroethylene. Polymer 48:4184-4195

22. Garg M, Mulliken AD, Boyce MC (2008) Temperature rise in polymeric materials during high rate deformation. ASME J Appl Mech 75:011009-1-011009-8

23. Nakai K, Yokoyama T (2008) Strain rate dependence of compressive stress-strain loops of several polymers. J Solid Mech Mater Eng 2:557-566

24. Naik NK, Shankar PJ, Kavala VR, Ravikumar G, Pothnis JR, Arya H (2011) High strain rate mechanical behavior of epoxy under compressive loading: experimental and modeling studies. Mater Sci Eng A 528:846-854

25. Okereke MI, Buckley CP, Siviour CR (2012) Compression of polypropylene across a wide range of strain rates. Mech TimeDepend Mater 16:361-379

26. Nakai K, Yokoyama T (2012) High strain-rate compressive properties and constitutive modeling of selected polymers. J Solid Mech Mater Eng 6:731-741

27. El-Qoubaa Z, Othman R (2014) Volume change in polyetheretherketone under compression loads over wide ranges of strain rate and temperature. J Strain Anal 49:315-324

28. Acharya S, Mukhopadhyay AK (2014) High strain rate compressive behavior of PMMA. Polym Bull 71:133-149

29. Kendall MJ, Siviour CR (2014) Experimentally simulating highrate behaviour: rate and temperature effects in polycarbonate and PMMA. Philos Trans R Soc A 372:20130202

30. Shim VPW, Yuan J, Lee S-H (2001) A technique for rapid twostage dynamic tensile loading of polymers. Exp Mech 41:122-127

31. Rae PJ, Brown EN (2005) The properties of poly(tetrafluoroethylene) (PTFE) in tension. Polymer 46:8128-8140

32. Gilat A, Goldberg RK, Roberts GD (2007) Strain rate sensitivity of epoxy resin in tensile and shear loading. J Aerosp Eng 20:75-89

33. Sarva SS, Boyce MC (2007) Mechanics of polycarbonate during high-rate tension. J Mech Mater Struct 2:1853-1880

34. Naik NK, Perla Y (2008) Mechanical behaviour of acrylic under high strain rate tensile loading. Polym Test 27:504-512

35. Fu S, Wang Y, Wang Y (2009) Tension testing of polycarbonate at high strain rates. Polym Test 28:724-729
36. Fleck NA, Stronge WJ, Liu JH (1990) High strain-rate shear response of polycarbonate and polymethyl methacrylate. Proc R Soc Lond A 429:459-479

37. Kolsky H (1949) An investigation of the mechanical properties of materials at very high rates of loading. Proc Phys Soc B 62:676-700

38. Tardif HP, Marquis H (1963) Some dynamic properties of plastics. Can Aeronaut Space J 9:205-213

39. Briscoe BJ, Hutchings IM (1976) Impact yielding of high density polyethylene. Polymer 17:1099-1102

40. Hamdan S, Swallowe GM (1996) The strain-rate and temperature dependence of the mechanical properties of polyetherketone and polyetheretherketone. J Mater Sci 31:1415-1423

41. Roland CM, Twigg JN, Vu Y, Mott PH (2007) High strain rate mechanical behavior of polyurea. Polymer 48:574-578

42. Rae PJ, Brown EN, Orler EB (2007) The mechanical properties of poly(ether-ether-ketone) (PEEK) with emphasis on the large compressive strain response. Polymer 48:598-615

43. Furmanski J, Trujillo CP, Martinez DT, Gray GT III, Brown EN (2012) Dynamic-Tensile-Extrusion for investigating large strain and high strain rate behavior of polymers. Polym Test 31:1031-1037

44. Millett JCF, Bourne NK (2000) The deviatoric response of polymethylmethacrylate to one-dimensional shock loading. J Appl Phys 88:7037-7040

45. Millett JCF, Bourne NK (2004) The shock induced equation of state of three simple polymers. J Phys D Appl Phys 37:2901-2907

46. Chen W, Zhou B (1998) Constitutive behavior of Epon 828/T403 at various strain rates. Mech Time-Depend Mater 2:103-111

47. Sadd MH, Morris DH (1976) Rate-dependent stress-strain behavior of polymeric materials. J Appl Polym Sci 20:421-433

48. Khan A, Zhang H (2001) Finite deformation of a polymer: experiments and modeling. Int J Plast 17:1167-1188

49. Porter D (1995) Group interaction modelling of polymer properties. Marcel Dekker, New York

50. Buckley CP, Dooling PJ, Harding J, Ruiz C (2004) Deformation of thermosetting resins at impact rates of strain. Part 2: constitutive model with rejuvenation. $J$ Mech Phys Solids 52:2355-2377

51. Porter D, Gould PJ (2009) Predictive nonlinear constitutive relations in polymers through loss history. Int J Solid Struct 46:1981-1993

52. Richeton J, Ahzi S, Daridon L, Rémond Y (2005) A formulation of the cooperative model for the yield stress of amorphous polymers for a wide range of strain rates and temperatures. Polymer 46:6035-6043

53. Richeton J, Ahzi S, Vecchio KS, Jiang FC, Adharapurapu RR (2006) Influence of temperature and strain rate on the mechanical behavior of three amorphous polymers: characterization and modeling of the compressive yield stress. Int J Solid Struct 43:2318-2335

54. Richeton J, Ahzi S, Vecchio KS, Jiang FC, Makradi A (2007) Modeling and validation of the large deformation inelastic response of amorphous polymers over a wide range of temperatures and strain rates. Int J Solid Struct 44:7938-7954

55. Khan AS, Lopez-Pamies O, Kazmi R (2006) Thermo-mechanical large deformation response and constitutive modeling of viscoelastic polymers over a wide range of strain rates and temperatures. Int J Plast 22:581-601

56. ASTM E9-89a (1995) Standard test methods of compression testing of metallic materials at room temperature. American Society for Testing and Materials, Philadelphia

57. Gray GT III, Blumenthal WR (2000) Split-Hopkinson pressure bar testing of soft materials. In: ASM Handbook ${ }^{\circledR}$, Vol. 8, 
Mechanical Testing and Evaluation. ASM International, Materials Park

58. Yokoyama T, Ogawa K (2003) Impact tensile properties of 6061 aluminium alloy to SUS 304 stainless steel friction-welded butt joints. Weld Int 17:514-523

59. Lindholm US (1964) Some experiments with the split Hopkinson pressure bar. J Mech Phys Solids 12:317-335

60. Bernatskii AD, Rabinovich AL (1964) Strain in certain crosslinked polymers. Polym Sci USSR 6:1166-1175

61. Dieter GE (1988) Mechanical metallurgy. McGraw-Hill, London

62. Swallowe GM (1999) Mechanical properties and testing of polymers: an A-Z reference. Kluwer Academic Publishers, Dordrecht

63. Brinson HF, Brinson LC (2008) Polymer engineering science and viscoelasticity: an introduction. Springer, New York

64. Ghorbel E (2008) A viscoplastic constitutive model for polymeric materials. Int J Plast 24:2032-2058

65. Malatyński M, Klepaczko J (1980) Experimental investigation of plastic properties of lead over a wide range of strain rates. Int $\mathbf{J}$ Mech Sci 22:173-183

66. Ramberg W, Osgood WR (1943) Description of stress-strain curves by three parameters. Technical note 902; National Advisory Committee for Aeronautics, Washington DC

67. McLellan DL (1967) Constitutive equations for mechanical properties of structural materials. AIAA J 5:446-450
68. Hight TK, Brandeau JF (1983) Mathematical modeling of the stress strain-strain rate behavior of bone using the RambergOsgood equation. J Biomech 16:445-450

69. Nunes RW, Martin JR, Johnson JF (1982) Influence of molecular weight and molecular weight distribution on mechanical properties of polymers. Polym Eng Sci 22:205-228

70. Hallam MA, Cansfield DLM, Ward IM, Pollard G (1986) A study of the effect of molecular weight on the tensile strength of ultrahigh modulus polyethylenes. J Mater Sci 21:4199-4205

71. Talbott MF, Springer GS, Berglund LA (1987) The effects of crystallinity on the mechanical properties of PEEK polymer and graphite fiber reinforced PEEK. J Compos Mater 21:1056-1081

72. Lee LH, Vanselow JJ, Schneider NS (1988) Effects of mechanical drawing on the structure and properties of PEEK. Polym Eng Sci 28:181-187

73. Hoy RS, Robbins MO (2006) Strain hardening of polymer glasses: effect of entanglement density, temperature, and rate. J Polym Sci Part B Polym Phys 44:3487-3500

74. Vorselaars B, Lyulin AV, Michels MAJ (2009) Microscopic mechanisms of strain hardening in glassy polymers. Macromolecules 42:5829-5842

75. Bouvard JL, Ward DK, Hossain D, Marin EB, Bammann DJ, Horstemeyer MF (2010) A general inelastic internal state variable model for amorphous glassy polymers. Acta Mech 213:71-96 